\title{
LOS GITANOS Y EL FLAMENCO EN EL CINE ESPAÑOL. Por la interculturalidad en educación secundaria
}

\author{
María Paz LÓPEZ-PELÁEZi ${ }^{\text {; Mila LÓPEZ-PELÁEZ }}{ }^{2}$ \\ ${ }^{1}$ Universidad de Jaén, España. ${ }^{2}$ Coventry University, UK \\ mlpelaez@ujaen.es,ab3333@coventry.ac.uk
}

\begin{abstract}
GYPSYS AND FLAMENCO IN SPANISH CINEMA. Encouraging Interculturalism in Secondary Education
\end{abstract}

Resumen: En las siguientes páginas se aboga por la utilización del cine como herramienta educativa en distintas áreas de educación secundaria. En concreto, se propone el visionado y análisis de películas y fragmentos de películas en los que miembros de la etnia gitana tienen un papel destacado. De acuerdo con el Curriculum Mil de la UNESCO, el visionado y el análisis de películas puede servir para hacer reflexionar al alumnado sobre conceptos complejos como son la raza o la identidad y para abordar cuestiones referentes a la supuesta objetividad del conocimiento. La reflexión sobre la imagen frecuentemente estereotipada que se ofrece de esta etnia en el cine es el punto de partida de una actividad que, basada en una pedagogía de raíz socrática, pretende facilitar la adquisición de conocimiento reflexivo-complejo, potenciar el espíritu crítico y desarrollar capacidades y competencias que serán indispensables al alumnado como ciudadanos de una democracia.

Abstract: Over the following pages we will argue in support of the use of cinema as a learning tool in different areas of secondary education. To be specific, we are proposing the viewing and analysis of films and parts of films in which people of Gypsy origin have a major role. In accordance with UNESCO's Curriculum Mil, we believe that the viewing and analysis of films can help lead pupils to reflect on complex concepts like race and identity, and to consider matters concerning the supposed objectivity of knowledge. The reflection on the frequently stereotyped image given to us of this ethnic group in cinema is the starting point for an activity which - based on Socratic pedagogy - aims at facilitating the acquisition of reflectivecomplex knowledge and developing critical thinking as well as the abilities and skills essential to students as citizens of a democracy.

Palabras clave: Cine, Gitanos, Flamenco, Educación Secundaria, Posmodernidad Cinema, Gypsy, Flamenco, Secondary Education, Posmodernism 


\title{
Introducción
}

Como es sabido, la posmodernidad postula la no existencia de una razón objetiva. El conocimiento científico se construye a partir de mapas conceptuales en los que juega un papel decisorio el discurso hegemónico y es tan sólo una interpretación que es compartida por un grupo de personas (Efland, Freedman y Stuhr, 2003). Resulta prioritario recordar que cada cultura escoge los hechos que quiere que sean recordados, selecciona aquellos que serán convertidos en "elementos de texto" y olvida otros que pasan a ser inexistentes (Lotman, 2000, p. 174). En el acercamiento a las culturas, el que describe se suele considerar a sí mismo como el portador del metalenguaje de descripción y cree que ese lenguaje (el suyo) se basa en la objetividad y en la neutralidad. Esta fragilidad epistemológica hace que haya que preguntarse: "¿no se logra la unidad al precio de olvidar todo lo que contradice esa unidad?" (Lotman, 2000: 114).

Frente a esto, desde la educación se hace necesaria la adopción de distintas perspectivas culturales que se opongan al etnocentrismo, es decir, a la creencia de que una cultura particular es la norma. Por otra parte, debemos tener presente que, como afirmara Edward Said,

\begin{abstract}
"no one today is purely one thing. Labels like Indian, or woman, or Muslim, or American are no more than starting-points, which if followed into actual experience for only a moment are quickly left behind. Imperialism consolidated the mixture of cultures and identities on a global scale. But its worse and most paradoxical gift was to allow people to believe that they were only, mainly, exclusively, white, or black, or Western, or Oriental" (1994: 407-408).
\end{abstract}

Se debe cuestionar la idea de que el conocimiento está exento de categorías y valores; que las creaciones humanas son algo abstracto, que están despolitizadas y desideologizadas y que no tienen relación con el contexto. El alumnado debe ser consciente de que la historia es un constructo personal que está influido no sólo por el autor/a y su entorno, sino también por el lenguaje empleado y que refleja la cultura dominante (Yilmaz, 2010).

Persiguiendo todos estos objetivos, en las siguientes páginas abogamos por la utilización del cine en educación secundaria a través de una breve selección de películas y fragmentos de películas que pueden ser abordados y analizados en el aula. Seguimos así las indicaciones que se recogen en el Curriculum Mil de la UNESCO (Wilson, Grizzle, Tuazon, Akyempong \& Cheung, 2011) en el que señala la importancia de preparar (o alfabetizar) a los alumnos/ as en este medio. En concreto, nuestro objetivo es introducir al alumnado en la reflexión de conceptos tan complejos como raza e identidad a través del visionado y el análisis de películas que traten cuestiones relacionadas con la etnia gitana. Pretendemos con ello hacer que se cuestionen el rol que desempeñan los miembros de esta minoría étnica (o, mejor aún, sobre el rol que se les hace desempeñar) y sobre la visión que se ofrece de su cultura, no sólo en el medio cinematográfico sino en la sociedad en la que vivimos.

Nuestro interés en la utilización del lenguaje fílmico en Educación Secundaria, persigue dos objetivos principales: 1.) Por un lado, servir de apoyo al desarrollo de competencias y contenidos que serán indispensables al alumnado como ciudadanos/as de una democracia. Como ya ha sido señalado en numerosas ocasiones, la educación en valores, tan necesaria en la sociedad actual en la que la crisis está amparando actitudes xenófobas, requiere de una formación competencial específica (Olveira, Rodríguez, Gutiérrez y Touriñán, 2005). Sin embargo, los planes de estudio no contemplan el aprendizaje de estos contenidos en profundidad, y como consecuencia no fomentan el desarrollo del espíritu crítico en los/as estudiantes en temas fundamentales para la convivencia democrática. Y esto es crucial si pretendemos 
tener un modelo de escuela que no segregue sino que incluya y sume, y que sea capaz de adaptarse a las situaciones que se presentan en un mundo cada vez más globalizado. Una escuela que rechace el etnocentrismo, la ignorancia, la falta de respeto por la diferencia y la asimilación de las creencias y costumbres de los grupos minoritarios a los del mayoritario. 2.) Por otro, pretendemos "educar espectadores" en un sentido similar, en muchos aspectos, al que se puede señalar con respecto a las artes visuales (Moreno, 2005). La importancia del cine en la sociedad en la que vivimos hace necesario abordar desde la educación esta "alfabetización cinematográfica", como se la denomina desde el mencionado Curriculum Mil de la UNESCO (Wilson y otros, 2011: 19). Mediante esta introducción al código fílmico, buscamos que los alumnos intenten ver más allá de lo se puede ver, pero sin caer en lo que Gombrich (en referencia a las artes visuales) denominara "la falacia del diccionario", es decir, considerar que existe un "código con una relación biunívoca entre signo y significación” (1983: 23-24). Como señala Martínez García de manera más concreta, "el cine no posee un código unívoco, no tiene reglas fijas y cerradas como ocurre con las lenguas naturales, un significante no remite unívocamente a un significado, sino a que a menudo lo no dicho implica mucho más que lo dicho" (2005: 257). Es necesario, por tanto, que los alumnos/as adquieran los mecanismos para descodificar el lenguaje cinematográfico.

Por último, pero no por ello menos importante, no puede olvidarse que el cine, como "obra de arte total a la que, desde siempre, han tendido todas las artes" (Keska, 2004: 302) es el medio idóneo para trabajar desde la interdiciplinariedad. La literatura, la música, la pintura, la danza, la arquitectura o la historia (entre otras) no sólo están presentes en el cine sino que se funden de manera perfecta en él, lo que incide aún más en su consideración como herramienta didáctica acorde a las tendencias educativas posmodernas.

\section{El cine como recurso educativo}

Es bien conocida la utilidad del cine como herramienta educativa. Butler, Zaromb, Keith y Roedige (2009) ya demostraron que el empleo de películas en la docencia mejoraba la retención de los estudiantes en un 50\%. Se dice que Thomas Edison afirmó que "las películas están destinadas a revolucionar nuestro sistema educativo y en pocos años más sustituirán, en gran medida, si no totalmente, la utilización de los libros de texto" (Reia-Baptista, 2012: 82). Sin llegar a alcanzar esta importancia en la educación, no se pueden olvidar las importantes contribuciones que el lenguaje fílmico ha realizado en distintas áreas del currículo. Así, ha sido utilizado para proteger y poner en valor el patrimonio cultural (Clarembeaux, 2010), para enriquecer las clases de historia (Stoddard y Marcus, 2010) y las de filosofía (Domínguez, 2006; Reia-Baptista, 2012) o para potenciar y promover un aprendizaje concreto en el alumnado (Reia-Baptista, 2012; Pardo-Rojas, 2011; Martínez-Salanova, 2010; Smith, 2009). De manera más general, también se ha destacado su potencial docente con los/as estudiantes de Primaria y Secundaria (Ambrós y Breu, 2007). Un ejemplo de esto último es el interesante manual de Martínez-Salanova Aprender con el cine, aprender de película: una visión didáctica para aprender e investigar con el cine (2002).

Como se ha señalado, el Curriculum Mil de la UNESCO apuesta en este sentido por el "análisis textual y contextual de los distintos objetos multimedia, como los filmes" (Wilson, Grizzle, Tuazon, Akyempong y Cheung, 2011: 37), e incluso, de manera más concreta, por "explorar los retratos de género y raza a través de un análisis de medios" (39). Ya que, como afirmara en este sentido Edgar Morin, "el cine favorece el pleno empleo de nuestra subjetividad, por proyección e identificación, nos hace simpatizar y comprender a aquellos que nos serían extraños o antipáticos en un momento cualquiera" (2000: 109).

Coincidimos con Chávez (2006) en que en el sistema educativo tradicional hay muy poco conocimiento reflexivo-complejo y las clases se suelen reducir con demasiada frecuencia a la exposición de contenidos por parte del profesor/a y a la recepción pasiva del 
alumno/a -la clase magistral-, sin que se fomente el interés por la investigación, la transferencia de conocimientos o la curiosidad por aprender. Debido a ello, en esta actividad nos decantamos por la utilización del método heurístico. Como es sabido, en este método, conocido como aprendizaje por descubrimiento, el alumno/a se convierte en un agente autónomo en la construcción del conocimiento. El papel del profesor/a quedaría por tanto reducido en esta actividad al de mero orientador; es decir, se presentaría como un recurso más que se pone a disposición del alumnado para resolver cuantas dudas puedan surgir en el proceso de documentación y reflexión. Se promueve de esta forma su participación activa mediante la indagación, el examen crítico y la reflexión, y se promueve el cuestionamiento en lugar del sometimiento a la autoridad. Esto significa apostar por un modelo de raíz socrática similar al que desarrollaron eminentes pedagogos como Jean Jacques Roussesu, Johann Heinrich Pestalozzi, Bronson Alcott, Horace Mann o John Dewey, entre otros (Nussbaum, 2012).

Esta actividad se puede enriquecer con un aprendizaje colaborativo, ya que de esta forma se potencia el desarrollo de las competencias interpersonales. Los/as estudiantes, trabajando en parejas heterogéneas y partiendo de la teoría explicada en el aula, tendrían que deconstruir la película, como forma de llegar a su sentido último, para, a partir de ahí, analizar no sólo cómo están estructuradas las partes sino también qué poderes subyacen en el discurso que se ofrece.

Además, la elevada complejidad semiótica y estética del cine y el empleo del método heurístico posibilita que los alumnos/as puedan diferir en sus opiniones. En este sentido, creemos que el cine, al igual que el resto de las artes, ayuda a tratar con la ambivalencia y, por tanto, a desarrollar el pensamiento divergente, tan importante en el mundo en el que vivimos (Burton, Horowitz y Abeles, 1999). El profesor/a puede además potenciar la adquisición de este tipo de pensamiento animando al alumnado para que se produzca esa diferencia en sus apreciaciones, siempre que estas se desarrollen en un marco de coherencia básico. Partimos de la premisa de que cualquier significado puede ser válido siempre que esté bien argumentado y razonado, lo que además se presenta como un ejemplo fehaciente de la no objetividad del conocimiento. Como se puede deducir de lo anterior, la utilidad del lenguaje fílmico, siguiendo a Reia-Baptista (2012), depende de la interactividad que provoque.

Con esta actividad pretendemos que los/las estudiantes adopten un punto de vista reflexivo y comprometido ante cualquier manifestación cultural que se les pueda presentar y que no proceda de la clase hegemónica; que desarrollen una mirada crítica y analicen la relación poder/saber; que recuerden la necesidad de conseguir una igualdad de oportunidades para los grupos minoritarios (en aspectos económicos, sociales o culturales), de respetar su identidad y de promover su integración cultural; que estimule el cuestionamiento en lugar de potenciar la asimilación de datos. En resumidas cuentas, se trata de que reflexionen sobre lo que es y lo que debe ser una democracia. Coincidimos con Pardo en que en esta sociedad del conocimiento en la que estamos inmersos, "al sistema educativo universitario le compete formar estudiantes con una gran sensibilidad social" (2011: 156). Pero no sólo eso. También pretendemos conseguir que los alumnos sean "capaces de reflexionar sobre [sus] propios procesos cognitivos [...] [sean] capaces de adquirir información de muchas fuentes y de la realidad, de sopesar alternativas y de arribar a conclusiones defendibles" (León, 2011: 168).

La complejidad del cine (y su elevado grado de signicidad) posibilita trabajar todos estos aspectos y además introducir al alumnado en complejos conceptos de identidad o raza. Como señalara Michel Clarembeaux (2010), en este tipo de actividades se debe evitar la formalidad y el academicismo en aras de fomentar un mayor grado de participación por parte de los estudiantes.

Aunque somos conscientes de las dificultades que entraña no circunscribir esta propuesta a un contexto curricular concreto, consideramos que su implementación es pertinente en muchas de las asignaturas que se cursan en Educación Secundaria y no exclusivamente en Educación para la Ciudadanía o Educación Ético-cívica. Creemos que estas cuestiones se 
pueden, y deben, abordar desde cuantas asignaturas sea posible en Enseñanza Secundaria. Así, y con respecto a la temática que proponemos, -la etnia gitana en el cine-, las áreas de Ciencias Sociales (Historia y Geografía), Lengua castellana y Literatura, Educación Artística o Música, entre otras, resultan muy adecuadas.

\section{Una aproximación a los gitanos y a la música flamenca}

Como señalara Robert Stam, “(d)urante gran parte del siglo, la teoría del cine en Europa y Norteamérica parece haber vivido de la ilusión de ser totalmente ajena a toda raza" (1999: 311-312). Fue en la segunda parte del siglo XX cuando surgió una producción cinematográfica destacada por parte de las minorías étnicas: el black british cinema, el cinema de la banlieu, el cinema beur o el kanak attack. Sin embargo, y a diferencia de lo que ocurrió en países como Gran Bretaña, Francia o Alemania, en España no se produjo un movimiento similar por parte de los colectivos minoritarios, por lo que el acercamiento a su problemática racial y social se ha realizado mayoritariamente desde la mirada hegemónica. Quizá por ello, la presencia de etnias en el cine español ha quedado reducida frecuentemente a señalar su especificidad -en el caso de la gitana, su relación con el patrimonio cultural-, con la elevada propensión a caer en el estereotipo que esto conlleva. Como afirmara Gordon W. Allport,

“dentro de las varias formas de pensar prejuicioso está el prejuicio étnico que es una antipatía que se apoya en una generalización imperfecta e inflexible y se convierte en una pauta de hostilidad en las relaciones interpersonales que se dirige contra un grupo entero o contra miembros individuales" (Garrido, 2003: 120).

El hecho de que el gitano/a no proceda de otro país - a diferencia del emigrante- pero sí de otra cultura (y suponga por tanto una amenaza a la identidad nacional), ha provocado que, en mayor o menor medida, esa visión estereotipada en el cine se haya visto acompañada de referencias hacia la tensión cultural que surge entre el colectivo mayoritario y el minoritario.

Son las películas en las que se presenta la realidad como un crisol de identidades y en las que la especificidad gitana y el encuentro-desencuentro entre lo minoritario y lo hegemónico se constituyen en la principal estrategia narrativa, las que resultan idóneas para profundizar y hacer reflexionar al alumnado en los conceptos de identidad o raza. De esta forma, frente a los metadiscursos modernos -a los "relatos especulativos", en palabras de Lyotard (1987: 32)- propios del dogma positivista, nos decantamos por un microrrelato dentro de un discurso educativo posmoderno.

El profesor/a debe enfatizar el hecho de que en estas películas se presenta una comunidad gitana imaginaria - siguiendo la terminología de Benedict Anderson (1983), en tanto que la identidad cultural debe ser considerada como una producción histórica, en continuo proceso de construcción, e imposible de ser representada por el discurso cinematográfico como algo acabado y bien delimitado. En opinión de Stuart Hall, y en el mismo sentido, “(c) ultural identity [...] is a matter of 'becoming' as well as of 'being'" (1989: 70).

Además, y como afirma Mónica Cantero (2010), el cine no solamente construye la identidad sino que transmite creencias socioculturales a la vez que sirve de espejo de la sociedad. De esta forma, la inmensa mayoría de las películas protagonizadas por miembros de la etnia gitana refuerzan esta identidad de comunidad imaginaria colectiva y los posicionan como "el Otro". Frente a esto, hay que hacer al alumnado consciente de que todas las identidades -tanto de raza, clase, género, religión o nación- son construcciones sociales. La identidad se relaciona en todo momento con aquello que uno no es (Sarup, 1996) 
También se debe ser cauteloso en el acercamiento a la cuestión de género en el cine. Realizar un análisis que sólo tenga en cuenta la diferencia masculino-femenino significa presuponer que no existe la variable económica y racial y reafirma las normas de la clase media blanca. Resulta crucial, por tanto, analizar detenidamente cómo se produce la intersección entre todos estos factores. En esta línea, Rosa L. Fregoso se muestra tajante al rechazar el discurso fílmico feminista que se limita a establecer binarismos de género, ya que esto lleva a ignorar "racial, class, and sexual subjectivities: the crucial differences among women, rather than simply between men and women" (1993: xxii).

Con respecto a la presencia de la música flamenca en todas las películas que se proponen (y a las que nos referiremos a continuación), debe señalarse, en primer lugar, que la importancia que tiene este arte en la cultura gitana, y la ignorancia del estudiante medio hacia este tipo de música hacen necesaria una investigación por parte de los alumnos. Y además, esta puede ser una forma idónea de introducir a los alumnos/as en la historia del pueblo gitano. Como dijera Rafael Cansinos,

"En la copla andaluza solloza [...] todo el dolor irredimible de un pueblo, todo el dolor irredimible de la humanidad, aunque expresado con los acentos de un duelo personal e íntimo. [...] La copla andaluza expresa la pasión inevitable de esos hombres y esas mujeres que la entonan, [...] exasperada [la pasión] por las injusticias históricas" (1976: 6).

El primer punto que debería ser abordado es el de la diferenciación entre el flamenco, es decir, la conversión del folklore en arte -como forma de "expresión de soledad, del yo que sufre e interpreta y asume las amarguras de todos los otros" (Ortiz Nuevo, 1985: 8)- y el flamenquismo -o rechazo de las poses y maneras aflamencadas o agitanadas (García Gómez, 1999). Relacionado con esto, resultaría interesante que el alumnado investigara sobre los ilustres miembros que tuvo esta corriente antiflamenquista y sobre el papel que desempeñaron en el Congreso de Cante Jondo de Granada de 1922, considerado como la "primera lucha colectiva organizada por un grupo de intelectuales a favor del flamenco" (Martínez Hernández, 1999: 67). Principalmente, el análisis de las figuras de Federico García Lorca (que dejó conocidas muestras de amor por el canto jondo en muchas de sus obras), Manuel de Falla -quien dijo que "el canto grave, hierático de ayer ha degenerado en el ridículo flamenquismo de hoy" (Grande, 1999: 33-34)- o Edgar Neville, director de Duende y misterio del arte flamenco, a la que os referiremos más adelante.

Creemos de la mayor importancia que los alumnos/as investiguen sobre el origen de la música flamenca. Comprobarán de esta forma que su desarrollo está estrechamente vinculado, como no podía ser de otro modo, a los avatares que sufrió el pueblo gitano desde que llegó a la Península Ibérica en plena Edad Media. De su nomadismo libre por las tierras españolas hasta las restricciones: primero con los Reyes Católicos y su Pragmática de 1499, posteriormente con las leyes dictadas en los reinados de Felipe II y Felipe IV y, especialmente -y ya en el reinado de Carlos III- con la Pragmática de 1631, que les supuso la prohibición de vagar por los caminos e incluso de hablar su propia lengua. Así surgió el cante, las Tonás sin acompañamiento, que no eran más que gritos de dolor en calabozos o en ghettos como el de Triana (Ortiz Nuevo, 1985).

Muchas de las películas protagonizadas por gitanos, y en las que el flamenco tiene un papel primordial, son un buen ejemplo de cómo todavía en el siglo XX este arte seguía siendo marginal. Creemos que se puede aplicar a la música (y baile) gitano la apreciación que Simon Frith realizara para la música negra americana: "it carried a sense of possibility denied in the labor market; it suggested a comradeship, a sensuality, a grace and joy and energy lacking in work" (Gaines, 1986: 74); es decir, la música ofrece una posibilidad que a los miembros de este etnia se le negaba en otros campos. Pero, paradójicamente, al mis- 
mo tiempo (y esto no puede ser olvidado), niega -o dificulta al menos- que se produzca su adaptación a la sociedad hegemónica (Hall, 1992: 42).

\section{Una propuesta docente}

No es nuestro objetivo hacer un listado exhaustivo de las películas que reflejan, o intentan reflejar, la especificidad gitana, pero sí queremos señalar algunas que pueden resultar útiles en la docencia y en las que, en mayor o menor medida, se hace referencia a aspectos que se suelen asociar a esta cultura. Así, a la ideología machista, chabolismo, marginalidad y reyertas entre gitanos; a cuestiones exclusivamente referidas a la mujer, como el maltrato por parte del marido (o la sumisión a él), la importancia de la virginidad y la boda gitana; o al recurrido folklorismo, con el flamenco (y el encasillamiento del gitano/a como cantante y bailarín), el mal de ojo o la buenaventura, como temas destacados.

Como apunta Garrido (2003), frecuentemente, los personajes que son interpretados por miembros de esta etnia suelen dejarse arrastrar por pasiones desenfrenadas y se subliman los sentimientos a los que se les vinculan. En cualquier caso, y como sigue señalando este autor, la presencia de un personaje gitano suele estar relacionado con la imagen estereotipada de su cultura y de su carácter y no ser algo meramente anecdótico. Y muy a menudo, en estas películas -como fiel reflejo de la realidad- se culpa a su cultura como la causante de su no integración en la sociedad.

En esta propuesta, vinculada a la educación en valores, se pretende que los alumnos/as reflexionen sobre la imagen negativa de los gitanos/as que se ha instalado en el cine y en cómo este arte se ha convertido en un receptor de los distintos prejuicios existentes en la sociedad. Es decir, buscamos que los alumnos sean conscientes del recorrido superficial sobre la especificidad gitana que se realiza en muchas (o más bien, en la gran mayoría) de las películas. Cómo en muchas de ellas, por ejemplo, sus miembros suelen estar relacionados con una actitud delictiva que puede ser de mayor o menos envergadura pero que desempeña un papel importante en la construcción de la identidad del personaje.

Proponemos la utilización de alguno/s de los siguientes filmes, de manera completa o a través del visionado de escenas concretas. A saber: Morena clara (de Florián Rey, 1936), Duende y misterio del arte flamenco (de Edgar Neville, 1952), Bodas de sangre y Amor brujo (de Carlos Saura 1980 y 1986), Los Tarantos (de Francisco Rovira Beleta 1963), La flor de mi secreto (de Pedro Almodóvar, 1996), Alma gitana (de Chus Gutiérrez, 1996) y Camarón (de Jaime Chávarri, 2005).

La primera de las películas que hemos mencionado, Morena clara, la que fuera la película más taquillera durante la II República, nos parece especialmente interesante por las posibilidades educativas que ofrece en el aula, al poner de manifiesto lo generalizado que estaban los prejuicios y la discriminación hacia esta etnia en la primera mitad del siglo pasado. Los alumnos/as pueden discutir sobre la doble consideración en la que parece tenerse a los miembros de esta etnia en la película. Por un lado, la numerosas connotaciones negativas que le son asociadas -su supuesta inferioridad moral, por ejemplo-; y, por otro, la contradicción que supone que, a pesar de lo anterior, se identifique lo gitano a lo andaluz, y ambos a lo español, o al menos a lo que hace que esta nacionalidad sea diferente al resto (Ruiz León, 2010). Además, y en un ejercicio de intertextualidad, hacer reflexionar al alumnado sobre el posible mensaje nacionalsocialista presente en la película y sobre la paradoja de que el ministro de propaganda de la Alemania nazi, Joseph Goebbels, utilizara este tipo de películas realizadas en España y protagonizadas por miembros de la etnia gitana -los mismos que ellos hacinaban en campos de concentración- como medio para transmitir valores nacionales (Estivill, 1997).

Con respecto a la película, sería interesante analizar cómo se trastocan los papeles que se presentan al comienzo del film y es la familia aparentemente honrada, la no-gitana y de 
clase social elevada, la que participa, voluntaria o involuntariamente, en reiteradas actividades delictivas frente a la ingenuidad del delito cometido por los gitanos. Especialmente relevante nos parece la parte que se desarrolla en el juzgado: las palabras que pronuncia el abogado defensor -"los gitanos viven en guerra continua con la sociedad. La culpa no es de ellos sino nuestra; en lugar de amor encuentran incomprensión, desconfianza, persecuciones y las puertas cerradas"-, la ridiculización que se realiza de la Justicia -encarnada en la figura del juez- o del mismo sistema -mediante la pareja de guardias civiles que acompañan a los dos delincuentes.

Especial detenimiento merece la música en esta película, uno de los elementos que más incide en la transmisión de los estereotipos tan difundidos en la época. Las tres coplas que canta Imperio Argentina en la película alcanzaron un éxito desconocido hasta el momento. Destaca La falsa monea, con letra de Ramón Perelló, y su conocido y elocuente estribillo: "gitana que tú serás como la farsa monea, que de mano en mano va y ninguno se la quea".

La segunda película que vamos a comentar, Los Tarantos tuvo bastante éxito en los años 60 y fue nominada a los Oscar como mejor película de habla no inglesa. En líneas generales, se puede resumir como una versión del Romeo y Julieta de Shakespeare (demasiado obvia no sólo por el argumento sino también por algunas referencias explícitas en distintos momentos de la película) pero trasladada a un barrio de chabolas a las afueras de Barcelona. Próxima al cine documental, en esta película se puede encontrar una cierta crítica social al mostrar no sólo la miseria de las barriadas de la ciudad sino también la marginación en la que se encontraba la etnia gitana en una época en la que la censura franquista no permitía este tipo de acercamientos.

El enfrentamiento se producirá entre el clan de los Zorongos, un grupo de gitanos/as que se había integrado y ascendido en la escala social, y los Tarantos, que seguían fieles a sus más antiguas costumbres. Aunque no se sepa muy bien cuál es la razón de su existencia, el odio ancestral es el principal elemento conector de la historia, bien por su presencia (especialmente en el caso del padre del clan de los Zorongos) o por su ausencia (encarnado en los enamorados Juana y Rafael, o en la amistad entre los pequeños de las dos familias). Y será el odio el que desencadene una desgracia que ya es previsible desde los comienzos de la cinta. Todo ello narrado con una clara pretensión de "acercarse a la realidad de su folklore musical" (Garrido, 2003: 166-167).

Uno de los elementos más impactantes de la película, y sobre el que debería centrarse parte de la investigación del alumnado, tiene que ver con la música y el baile. Este último representado magistralmente en las figuras de una soberbia Carmen Amaya (en su papel de madre de Rafael), de Sara Lezana o Juana (especialmente en el momento en el que conoce y se enamora de Rafael) o de Antonio Gades, el alegre y vividor amigo de Rafael (recomendamos la escena de baile que se desarrolla con el telón de fondo de las mangueras de agua limpiando las calles de la ciudad).

La siguiente película a la que nos vamos a referir, La flor de mi secreto es un reflejo de la realidad contemporánea española y en ella desempeña un papel importante la marginalidad de una parte de la sociedad que en ocasiones pasa desapercibida al resto. A través de los dos personajes gitanos más importantes (Blanca, asistenta y bailaora profesional, y Antonio, su hijo), Almodóvar denuncia esa realidad social y pone de manifiesto esa situación paradójica que ya señalábamos en Morena clara:

"por un lado, los personajes gitanos eran uno de los ingredientes que se usaron más a menudo para dotar de ambiente típicamente español a la producción cinematográfica nacional pero, por otro, solían aparecer representados como individuos en cierto modo desviados de la norma de lo español" (Santaolalla, 2005: 29). 
Es decir, se trata del gitano/a "que por una parte es la privilegiada representación simbólica de la identidad nacional desde el romanticismo y simultáneamente el ejemplo esencial de marginado al cuerpo social nacional" (Colmeiro, 1997: 122-123). Esta contraposición de sentimientos hacia 'lo gitano' que está tan presente en nuestra realidad social actual, queda claramente reflejada en diferentes momentos de la película: así, por un lado, se puede señalar la admiración que provoca entre el público la escena de baile flamenco entre Blanca y su hijo, una de las hermosas de todo el film, y, por otro, el desprecio que se advierte en los mismos personajes que los felicitaban por su arte y que se revela a través de comentarios despectivos del tipo "ni que fuera yo gitana". Por otra parte, y como afirma Garrido, en este film no se encuentra ningún descriptor de tipo antropológico, es decir, aquellos que sirven para retratar o intentar reflejar la identidad gitana, sino que la presencia de miembros de esta etnia en el film se manifiesta exclusivamente a través de referentes folklóricos (2013).

También debe destacarse que los gitanos no son los únicos representantes de la otredad en La flor de mi secreto. Almodóvar crea en esta película un "encuentro transcultural" (Colmeiro, 1997: 123) entre negros y gitanos, cuyo análisis por parte de los alumnos/as puede resultar del mayor interés.

Otra de las películas mencionadas, Alma Gitana, se nos presenta como un intento consciente de dar una aproximación real a la problemática de la mujer gitana en la sociedad contemporánea española. La protagonista, Lucía, es una joven atípica por su condición de universitaria, pero que, a pesar de ello, acepta estar sometida al hombre (al padre y al hermano). A grandes rasgos, la película narra la relación sentimental que se establece entre Lucía y Antonio, un payo vividor y mujeriego con aspiraciones (nada reales) de convertirse en un gran bailaor de flamenco. La película nos muestra cómo se consolida su relación y cómo ésta ocasiona que ambos jóvenes se enfrenten, aunque con distinta intensidad, a la familia de ella y a las normas impuestas por la tradición. Aunque Lucía se muestra abiertamente contraria a algunas de las costumbres generalizadas en su colectivo (el ritual del pañuelo en las bodas o los matrimonios forzados) y rechaza la agresión de la mujer por parte del marido, acata otras muchas normas, haciendo que su papel dentro de la película no pueda considerarse completamente subversivo.

Nos parece especialmente interesante la escena que se desarrolla en la cocina y en la que Lucía se enfrenta verbalmente a su madre y hermana al posicionarse en contra de la violencia de género: “¿Y a ti quién te ha hecho eso otra vez? ¿el bruto de tu marido, verdad? [...] que tú lo que tienes que hacer es dejarle ya de una vez". La madre, no obstante, resulta ser una figura fálica dentro del hogar patriarcal por lo que simplemente responde: "que las cosas de tu hermana y su marío (sic) ellos se las apañen" demostrando con esta afirmación la consagración de la ley del Padre.

Como ya se ha indicado con anterioridad, en la inmensa mayoría de las películas que tratan sobre esta etnia, la música flamenca es utilizada para reforzar la posición que se nos presenta de esta etnia y sirve como herramienta constructiva de una identidad fija. Así ocurre en Bodas de sangre y Amor Brujo, de Carlos Saura. Ambas son, como señala Thibaudeau (2007: 26), "ejemplos del repertorio flamenco cinematográfico" de su director y un reflejo de la renovación que sufrió este arte en la década de los 70. Debe hacerse notar que en sus películas están presentes, y especialmente en la segunda de las mencionadas, grandes dosis de folklorismo. Muy diferente en este sentido es Camarón. Creemos que es un buen ejemplo de película que no cae en los tópicos, aunque ciertamente están presentes muchos de los temas que se suelen relacionar con esta etnia: el fuerte temperamento que se asocia a los gitanos, la situación de marginalidad en la que se mueven muchos de sus miembros o su relación con las drogas. Al igual que en Camarón, el flamenco también tiene una importante presencia en la película-documental Duende y misterio del arte flamenco, de Edgar Neville. En ella, el director hace un recorrido histórico en el que deja patente su amor y respeto por este arte. Resultaría interesante analizar la repercusión que tuvo la Generación del 27 y el 


\section{Congreso de Cante Jondo de Granada (1922) en la gestación de esta película.}

Tras el visionado de las películas propuestas, debería hacérseles notar a los alumnos/as cómo, mientras que en la cultura dominante una persona es sólo una persona, un miembro de la cultura minoritaria siempre es visto como representante del colectivo al que pertenece. Es decir, sus defectos como personaje se suelen generalizar y también explicar en base a su etnia (Thompson, 1997).

\section{Para finalizar}

Para que el aprendizaje sea significativo (y como ya formulara Dewey) en el aula se debe aunar la teoría y la práctica. La enseñanza no debe centrarse tan sólo en conceptos sino que, como señalara Leiva (2010), debe basarse en aspectos reflexivos, críticos y actitudinales. Si pretendemos superar el dogma positivista y la actitud etnocentrista, tenemos que fomentar entre nuestro alumnado el cuestionamiento ante la realidad que se nos presenta. Además, en educación no deben rehuirse los conflictos cognitivos que provoca la existencia y la convivencia de distintas identidades en la sociedad, ya que entonces "se reduce a la persona en su competencia crítica; al eludir el conflicto social, reduciendo la realidad colectiva al individualismo, se desprovee a la ciudadanía de la capacidad de mejora colectiva" (Ruiz- Román, Calderón-Almendro y Torres-Moya, 2011: 591).

Como hemos destacado en las páginas precedentes, el cine, como artificio semiótico de difícil descodificación, es una poderosa herramienta docente que posibilita múltiples lecturas, la adopción de distintas perspectivas e interpretaciones de la realidad y el desarrollo de un pensamiento reflexivo. Hay que tener en cuenta que, frecuentemente, es tan sólo a través del cine y del "imaginario artificial" que crea -en palabras de Martínez García (2005: 257)-, como tenemos conocimiento de colectivos que nos resultan ajenos, se construye su identidad y se transmiten sus creencias. Al mismo tiempo, la poderosa influencia del cine en nuestro subconsciente ocasiona que la reproducción simulada de la realidad que realiza sustituya al objeto que reproduce, creando en ocasiones una imagen distorsionada que no se corresponde con sus referentes, pero que "es más consistente e intensamente real que la realidad misma" (Martínez García, 2005: 257). Como afirmara Braudillard, "la era de la simulación se abre, pues, con la liquidación de todos los referentes — peor aún: con su resurrección artificial en los sistemas de signos" (1978: 7).

Por todas estas razones, el visionado de películas nos parece el medio idóneo para introducir al alumnado en cuestiones de identidad y para hacerles reflexionar sobre la presencia de la visión hegemónica en la construcción de "el Otro". Está claro que la educación intercultural es una competencia que requiere formación específica y es un tema de interés público que resulta necesario en la formación de una conciencia cívica (Olveira, Rodríguez, Gutiérrez y Touriñán, 2005). Debemos conseguir que nuestros alumnos dejen de considerar que la piel blanca es lo normal y neutral. Es la única forma de conseguir que la que no lo es estigmatice al grupo y haga que sus individuos sean vistos como excepcionales o exóticos. $\mathrm{Si}$, como dijera Gordon W. Allport, "las opiniones previas se convierten en prejuicios solamente si al enfrentarlas con nuevos conocimientos no son reversibles" (Garrido, 2003: 120), es un imperativo desarrollar el espíritu crítico en el alumnado. Sólo así, en nuestra opinión, tendremos garantías de vivir en una sociedad que sea realmente democrática.

\section{Bibliográfia}

AMBRÓS, A. y BREU, R. (2007) Cine y educación el cine en el aula de Primaria y Secundaria. Barcelona, Graó.

ANDERSON, B. (1983) Imagined Communities. Norfolk (Reino Unido), Verso Editions.

BRAUDILLARD, J. (1978) Cultura y simulacro. Barcelona, Kairós. 
BURTON, J., HOROWITZ, R. y ABELES, H. (1999) Learning In and Through the Arts: Curriculum Implications. (http://artsedge.kennedy-center.org/champions/pdfs/Learning.pdf) (consultado el 5 de junio de 2015)

BUTLER, A., ZAROMB, F., KEITH B. y ROEDIGER, H. (2009) Using popular films to enhance classroom learning: The good, the bad, and the interesting. Psychological Science 20 (9), pp. 1161-1168.

CANSINOS, R. (1976) La copla andaluza. Madrid, Demófilo.

CANTERO, M. (2010) "Visions and Voices of the Self in Take my Eyes", en Laviosa, F.: Visions of Struggle in Women's Filmmaking in the Mediterranean. (pp. 45-63), New York, Palgrave MacMillan.

CHÁVEZ, H. (2006) Una aproximación metodológica interdisciplinaria en la educación artística. Discurso visual, 7. (http://discursovisual.cenart.gob.mx/dvwebne7/aportes/apochaves. htm) (consultado el 30 de marzo de 2015)

CLAREMBEAUX, M. (2010) Film Education: Memory and Heritage. Comunicar 35 (18), pp. 2531. DOI:10.3916/C35-2010-02-02

COLMEIRO, J. F. (1997) Del rosa al negro: Subtextos culturales en La flor de mi secreto. Arizona Journal of Hispanic Cultural Studies 1, pp. 115-128.

DOMÍNGUEZ, E. (2006) El cine entre el entretenimiento y la cultura creativa. Una filmografía. Arte, Individuo y Sociedad 18, pp. 77-13.

EFLAND, A., FREEDMAN, K. y STUHR, P. (2003) La educación en el arte posmoderno. Barcelona, Paidós (Orig. 1996).

ESTIVILL, J. (1997) "Comercio cinematográfico y propaganda política entre la España franquista y el Tercer Reich". Film-Historia. VII (2), 113-130. (http://www.publicacions.ub.es/bibliotecaDigital/cinema/filmhistoria/art.Estivill.pdf) (consultado el 10 de julio de 2016)

FREGOSO, R. (1993) The Bronze Screen: Chicana and Chicano Film Culture. Minneapolis (EEUU), University of Minnesota Press.

GAINES, J. (1986) White Privilege and Looking Relations: Race and Gender in Feminist Film Theory. Cultural Critique 4, pp. 59-79.

GARCÍA GÓMEZ, G. (1999) "El arte flamenco en las dos Españas (Principio y fin del antiflamenquismo)", en Carmona, A.: El flamenco en la cultura española. (pp. 11-26), Murcia, Servicio de Publicaciones de la Universidad de Murcia.

GARRIDO, J. A. (2003) Minorías en el cine. La etnia gitana en la pantalla. Barcelona, Universidad de Barcelona.

GOMBRICH, E. (1983) Imágenes simbólicas. Madrid, Alianza Editorial.

GRANDE, F. (1999) ““¡Don Manuel, que nos vamos!’ Falla. Granada 1922. El ‘Concurso de Cante Jondo."”, en Carmona, A.: El flamenco en la cultura española. (pp. 27-63), Murcia, Servicio de Publicaciones de la Universidad de Murcia.

HALL, S. (1989) Cultural Identity and Cinematic Representation. Framework 36, pp. 68-81.

KĘSKA, M. (2004) La búsqueda de la obra de arte total en el cine contemporáneo: Derek Jarman. Espacio, tiempo y forma. Historia del arte 17, pp. 295-306.

LEÓN, J. (2011) La unidad de producción de conocimiento como respuesta a los desafíos metodológicos de la educación en el tercer milenio. Aula 17, pp. 159-169.

LEIVA, J. (2010) Práctica de la interculturalidad desde la perspectiva docente: análisis y propuestas pedagógicas. Cultura y Educación 22 (1), pp. 67-84.

LOTMAN, I. (2000) La semiosfera. Semiótica de las artes y de la cultura. Madrid, Cátedra.

LYOTARD, J. F. (1987) La condición postmoderna. Informe sobre el saber. Madrid, Cátedra.

MARTÍNEZ GARCÍA, M. A. (2005) Controversias acerca del cine y el intercambio cultural. Сomunicación 3, pp. 253-263.

MARTÍNEZ HERNÁNDEZ, J. (1999) "Los intelectuales con el flamenco: Del concurso de Granada a nuestros días", en Carmona, A.: El flamenco en la cultura española. (pp. 65-90), Murcia, Servicio de Publicaciones de la Universidad de Murcia.

MARTÍNEZ-SALANOVA, E. (2002) Aprender con el cine, aprender de película. Una visión didáctica para aprender e investigar con el cine. Huelva, Grupo Comunicar

MARTÍNEZ-SALANOVA, E. (2010) Education in European Cinema and Society's Exclusion of the Young. Comunicar 35, pp. 53-60. DOI:10.3916/C35-2010-02-05 
MORENO, M. I. (2007) Educar espectadores: propuestas expositivas y dinamización. Comunicar 28, pp. 221-228.

MORIN, E. (2000) Los siete saberes necesarios a la educación del futuro. Caracas, UNESCO.

NUSSBAUM, M. C. (2012) Sin fines de lucro. Por qué la democracia necesita de las humanidades. Madrid, Katz.

OLVEIRA, M. E., RODRÍGUEZ, A., GUTIÉRREZ, M. C. y TOURIÑÁN, J. M. (2005): Modelos interculturales. Cuestiones conceptuales para el desarrollo de estrategias de intervención. Revista de Investigación en Educación, 2. (http://webs.uvigo.es/reined/ojs/index.php/ reined/article/viewFile/15/6) (consultado el 10 de febrero de 2017)

ORTIZ NUEVO, J. L. (1985) Pensamiento político en el cante flamenco. Sevilla, Biblioteca de Cultura Andaluza.

PARDO MARTÍNEZ, L. P. (2011) La función de la Universidad en las sociedades del conocimiento. Aula 17, pp. 145-158.

PARDO-ROJAS, A. (2011) Autoaprendizaje experiencial y cine: el caso de la película Paraíso Travel. Arte, Individuo y Sociedad 23 (2), pp. 55-67.

REIA-BAPTISTA, V. (2012) La alfabetización fílmica: apropiaciones mediáticas con ejemplos de cine europeo. Comunicar 39, pp. 81-90. DOI: 10.3916/C39-2012-02-08

RUIZ LEÓN, C. (2010) Cine y mestizaje. Las alianzas amorosas interculturales en el cine español a través de tres ejemplos: El negro que tenía alma blanca (1927), Morena Clara (1936) y El próximo Oriente (2006). Revista valenciana d'Etnologia 5, pp. 137-152.

RUIZ-ROMÁN, C., CALDERÓN-ALMENDROS, I. y TORRES-MOYA, F. J. (2011) Construir la identidad en los márgenes de la globalización: educación, participación y aprendizaje. Cultura y Educación 23 (4), pp. 589-599. DOI

SAID, E. (1994) Culture and Imperialism. New York, Vintage Books.

SANTAOLALLA, I. (2005) Los “Otros". Etnicidad y "raza” en el cine español contemporáneo. Zaragoza, Prensas Universitarias de Zaragoza.

SARUP, M. (1996) Identity, Culture and the Postmodern World. Athens (EEUU), University of Georgia Press.

SMITH, G. W. (2009) Using feature films as the primary instructional medium to teach organizational behavior. Journal of Management Education 4 (33), pp. 462-489.

STAM, R. (1999) Teorías del cine. Una introducción. Barcelona, Paidós.

STODDARD, J. D. y MARCUS, A. S. (2010) More than 'showing what happened': Exploring the potential of teaching history with film. The High School Journal 93 (2), pp. 83-90.

THIBAUDEAU, P. (2007) Del repertorio musical y coreográfico al repertorio cinematográfico: el caso de Carlos Saura. Pandora: Revue D'etudes Hispaniques 7, pp. 21-30.

THOMPSON, A. (1997) Anti-Racist Education. Curriculum Inquiry 27(1), pp. 7-44.

WILSON, C., GRIZZLE, A., TUAZON, R., AKYEMPONG, K. y CHEUNG, C. (2011) Alfabetización mediática e informacional. Curriculum para profesores. París, UNESCO.

YILMAZ, K. (2010) Postmodernism and its Challenge to the Discipline of History: Implications for History Education. Educational Philosophy and Theory 42 (7), pp. 779-795. 